\title{
A mulher na cena literária em Paulina Chiziane E ConceiçÃo Evaristo: diÁlogos de RESISTÊNCIA
}

\section{The woman in the literary scene by Paulina Chiziane AND ConceiçÃo EVARISTO: DIALOGUES OF RESISTANCE}

DOI: 10.11606/issn.1981-7169.crioula.2017.137540

RESUMO: O objetivo deste artigo é analisar os contos "As cicatrizes do amor", da moçambicana Paulina Chiziane, e "Quantos filhos Natalina teve?", da afro-brasileira Conceição Evaristo. Para tanto, considera-se o conceito de gênero como categoria de análise. Ambas as escritoras evidenciam a muIher na cena literária e é possível reconhecer, em seus textos, diálogos de resistência, pois abordam a condição feminina mediante a (des)construção da imagem materna.

ABSTRACT: This paper intends to study the short stories "As cicatrizes do amor", by the Mozambican writer Paulina Chiziane, and "Quantos filhos Natalina teve?", by the Afro-Brazilian writer Conceição Evaristo. Therefore, it considers the concept of gender as a category of analysis. The authors demonstrate the woman in the literary scene and it is possible to recognize dialogues of resistance in the plot. They express the female condition through the (de)construction of the maternal image.

PALAVRAS-CHAVE: Mulher; Prosa contemporânea; Resistência; Imagem materna.

KEYWORDS: Woman; Contemporary prose; Resistance. Maternal image.

1 Doutora em Letras e Linguística pela Universidade Federal de Goiás (UFG). Professora da Universidade Estadual de Goiás (UEG) no Curso de Licenciatura Plena em Letras - Português/lnglês, Câmpus Pires do Rio, e no Programa de Pós-Graduação Stricto Sensu em Língua, Literatura e Interculturalidade (POSLLI), Câmpus Cora Coralina.. 
REVISTA CRIOULA N² 20 - 2 SEMESTRE/2017

\section{INTRODUÇÃO}

abordagem da prosa contemporânea requer que o crítico esteja aberto a visitar inúmeras obras de difeE rentes vozes que não estão reunidas por um projeto único e coeso, mas sim apresentam suas características específicas e que, por coincidências e/ou circunstâncias históricas e culturais, podem apresentar temas e estilos convergentes que permitem analogias. Isso pode ser verificado ao se estabelecer relações entre as escritas literárias da moçambicana Paulina Chiziane e da afro-brasileira Conceição Evaristo.

Em linhas gerais, a ficção moçambicana contemporânea tem-se apresentado de forma inovadora com a prosa poética e revelado características marcantes como a consciência crítica do próprio fazer literário, a experimentação de palavras, o humor, o trágico, a ironia, a paródia, a sátira, a crítica à burguesia urbana, a tradição oral, a memória, a valorização do contador de histórias, as manifestações culturais do país, a reflexão sobre a realidade e as contradições geradas pelo processo de colonização, as consequências da guerra, entre outras.

Na ficção brasileira contemporânea, por sua vez, segundo Beatriz Resende (2008), há múltiplas linguagens e tendências, incorporação de signos teatrais no processo de criação artística, bem como de signos advindos de outras artes, tais como cinema e música. Desenvolvem-se distintos modos da relação com o leitor, o trágico, o humor, o humor negro, o absurdo, a ironia, a violência, a irreverência a memória, entre outros.

A partir dessas observações, pode-se constatar que muitas particularidades coincidem tanto na prosa moçambicana 
quanto na brasileira. Em particular, no que se refere à Chiziane e à Evaristo, é possível afirmar que elas posicionam a mulher como protagonista de seus enredos e evidenciam a resistência feminina ao autoritarismo de uma sociedade patriarcal. Com o propósito de demonstrar essa possível analogia temática, este trabalho seleciona como foco de análise os contos "As cicatrizes do amor" (de Chiziane) e "Quantos filhos Natalina teve?" (de Evaristo), os quais tratam da condição feminina mediante a (des)construção da imagem materna.

Antes de se estabelecer esta abordagem, podem ser aproximados aspectos biográficos das referidas escritoras como a origem social humilde, as experiências de vida no subúrbio de grandes cidades, a paixão pelas letras, a consciência política e a visão crítica da sociedade pós-colonial. Do vivido, elas trazem a matéria de suas narrativas, criando histórias simples que refletem sobre o cotidiano. Nesse sentido, Paulina Chiziane apresenta-se como uma contadora de histórias e revela a diversidade cultural do espaço moçambicano. Conceição Evaristo, por sua vez, reconhece-se também como contadora de histórias graças à "escrevivência", que são as vivências do corpo de mulher negra no contexto de diversidade cultural brasileiro.

\section{O lugar da MULher COMO FICCIONISTA}

Para refletir sobre o lugar da mulher como ficcionista, inevitavelmente, passa-se pelo feminismo que é significativo para a transformação da sociedade e para o campo dos Estudos Culturais. "Falar em Estudos Culturais é, igualmente, propor 
um debate que passa por temas contemporâneos com o feminismo, o pós-modernismo, pós-colonialismo e o latino-americanismo." (RESENDE, 2002, p. 26). Isso porque se referem a uma área interdisciplinar que investiga os diversos aspectos culturais de uma dada sociedade, servindo-se de outras disciplinas como a Antropologia, a Sociologia, a História, a Teoria Literária, entre outras. Desse modo, o campo dos Estudos Literários são ampliados, por se dedicarem a inúmeras questões como é o caso dos estudos de gênero, identidade e alteridade.

Em especial, a questão da alteridade assume relevância na década de 1970 e, segundo Heloísa Buarque de Hollanda (1994, p. 8): "No plano político e social, esse debate ganha terreno a partir dos movimentos anticoloniais, étnicos, raciais, de mulheres, de homossexuais e ecológicos que se consolidam como novas forças políticas emergentes". Diante disso, a tentativa de definir a especificidade da escrita feminina, do que seria uma identidade feminina, conduz ao estabelecimento do conceito de gênero como categoria de análise.

O gênero constitui-se pelas relações sociais em que se evidenciam as diferenças entre os sexos e as relações de poder, tão marcantes na história social e cultural e que se instauram por meio da linguagem como uma violência simbólica, como bem pontua Constância Lima Duarte (1997). Por essas razões, as mulheres, por muito tempo, apareceram como um grupo silenciado e marginalizado.

Ao comentar sobre várias escritoras, Cecil Zinani (2010, p. 22) destaca a percepção literária das mulheres escritoras e enfatiza que estas "conseguiram ultrapassar diversas barreiras, primeiramente, no que tange à produção literária, tor- 
nando-se sujeito e não mais objeto de representação". Dessa maneira, o cenário literário, que era predominantemente marcado pela masculinidade, abre espaço à autoria feminina.

A resistência em torno do uso do vocábulo feminismo no Brasil, segundo Duarte (2003), não é adequada ao movimento legítimo que foi ao transformar as relações entre homens e mulheres. Por isso, a autora propõe a seguinte definição: '“feminismo' poderia ser compreendido em um sentido amplo, como todo gesto ou ação que resulte em protesto contra a opressão e a discriminação da mulher, ou que exija a ampliação de seus direitos civis e políticos, seja por iniciativa individual, seja de grupo." (DUARTE, 2003, p. 1).

No que se refere às contribuições recíprocas entre a história das mulheres e o movimento feminista, Rachel Soihet (1997) esclarece que os historiadores sociais viam as muIheres de modo homogêneo, como "pessoas biologicamente femininas que se moviam em papéis e contextos diferentes, mas cuja essência, enquanto mulher, não se alterava", isto é, elas apresentavam uma identidade coletiva que favoreceu o movimento feminista nos anos de 1970. Disso, resultou a oposição entre homem e mulher, mas, no entanto, ao final daquela década, surgiram questionamentos acerca da viabilidade da categoria mulheres, introduzindo a diferença como um aspecto a ser discutido.

A ideologia política do feminismo passa a ser uma "tendência teórica", a chamada Crítica Feminista, a qual se articula com a História e a Política. Considerando o caráter crítico e político da discussão feminista no "campo da crítica da cultura", no feminismo anglo-americano, particulariza-se "a escrita 
das mulheres como o lugar potencialmente privilegiado para a experiência social feminina." (HOLLANDA, 1994, p.11).

Ao tratar sobre a escrita e a cultura da mulher, Elaine Showalter (1994) afirma: "uma teoria baseada em um modelo da cultura da mulher pode proporcionar, acredito eu, uma maneira de falar sobre a especificidade e a diferença dos escritos femininos mais completa e satisfatória". Isso porque a teoria da cultura inclui ideias acerca "do corpo, da linguagem e da psique da mulher", interpretando-as "em relação aos contextos sociais nos quais elas ocorrem" (SHOWALTER, 1994, p. 44).

No que se refere a papéis e comportamentos femininos, a escrita das mulheres se distingue mediante a relação cultural complexa e historicamente fundamentada. Por essa razão, Showalter (1994) propõe a crítica ginocêntrica, a qual "deve ser a de delinear o locus cultural preciso da identidade literária feminina e a de descrever as forças que dividem um campo cultural individual das escritoras" (SHOWALTER, 1994, p. 51). Desse modo, a teoria literária feminista concentra sua atenção no estudo da relação entre a identidade literária feminina e o campo cultural onde as escritoras se inserem, devido a seus textos trazerem um caráter político.

As mulheres escritoras conscientizam-se e questionam sua própria condição, conquistam espaços e marcam presença no meio literário. Na caracterização da literatura escrita por elas, os aspectos culturais afetam a percepção do mundo apresentada nos textos. Mediante a representação do gênero feminino, evidenciam-se a contestação e a subversão dos comportamentos que são impostos culturalmente pela sociedade patriarcal à mulher. As ficcionistas suscitam a reflexão de seus 
leitores sobre o questionamento da representação tradicional do gênero e sobre o papel exercido por mulheres que se inserem na esfera pública da literatura como escritoras. Reavaliam os valores sociais contemporâneos e conscientizam a mulher da importância de sua liberação e ruptura da repressão que lhe é, muitas vezes, imposta nas práticas culturais.

A participação da mulher, no âmbito sociocultural, relaciona-se à emancipação feminina. Traz como tema a condição da mulher, a busca da identidade feminina, configurando-se em uma literatura de mulheres. No meio literário, poderiam ser citados vários nomes de mulheres escritoras cujas obras abordam a condição feminina entre outros temas. Nesse grupo, incluem-se os nomes de Chiziane e de Evaristo, das quais a seguir se analisam os contos já mencionados.

\section{A (DES)CONSTRUÇÃO DA IMAGEM MATERNA NOS CONTOS}

O conto "As cicatrizes do amor", escrito por Paulina Chiziane em 1989, narra a história de Maria. O termo "cicatrizes" metaforiza as dores e estabelece paradoxo com o vocábulo "amor" - que remeteria ao sentimento positivo de afeição, mas que recebe o sentido de sacrifício - correspondendo à memória que provoca sofrimento a quem a evoca. $O$ enredo é introduzido pela narradora que está em uma "rodada de mulheres sentadas na areia e os homens nas cadeiras" (CHIZIANE, 1994, p. 128), cena que indica o ritual de contação de histórias e figurativiza a posição social subalterna das mulheres em relação aos homens que ocupam assentos em plano superior. 
O espaço corresponde à caserna de Maria, na Ilha de Inhaca (leste de Maputo), onde estão os "deslocados", referindo-se à guerra. De modo indefinido, a narradora anuncia que "Alguém folheia um jornal velho" (CHIZIANE, 1994, 129), sugerindo o isolamento do local e o atraso das notícias. Em seguida, estabelece-se o diálogo antagônico entre homem e mulher acerca da notícia do abandono de crianças:

- Veja isto, compadre. Duas crianças abandonadas pelas mães.

[...]

- O que Ihes aconteceu?

- Alguém as deitou fora. As mulheres estão doidas.

- São efeitos do PRE - respondeu o outro. [...]

- A maldade nasceu antes da humanidade. A culpa cabe às mães mas é de toda a sociedade - sentenciou a mulher".

- Não fuja da verdade, comadre, que a culpa está com as mulheres. [...]" (CHIZIANE, 1994, p. 129, grifo nosso).

De um lado, o homem acusa as mulheres; de outro, a mulher, que é Maria, defende-as, assumindo a posição de narradora:

- O que vocês não sabem - disse Maria - é que cada nascimento tem uma história e cada acção, uma razão. Na minha juventude cometi o mesmo crime, ou melhor, ia cometê-lo. Tudo por causa desse amor amargura, amor escravatura, que transtorna, que enfeitiça, fazendo do amante a sombra do amado. (CHIZIANE, 1994, p. 129, grifo nosso). 
A protagonista conta que, ousada, engravidou-se do homem dos seus "sonhos", remetendo à idealização do amor. No entanto, por seu amado ser pobre, sem condições de honrar as regras da tradição do lobolo (dote), foi rejeitado por seu pai, levando o jovem a partir para Johannesburg. Constata-se que a mulher que se torna mãe-solteira não é aceita socialmente. Assim: "Quinze dias depois do nascimento da criança, o meu pai disse: fora desta casa" (CHIZIANE, 1994, p. 130).

A criança parecia morta e ela pensou em desfazer-se dela:

Meus olhos inquietos procuravam uma lixeira, uma vala, uma corrente de água, esgotos, um lugar qualquer, para desfazer-me do meu fardo. Trágica peregrinação! Chorava pelo amor que me fazia chorar; pela terra mãe que deixei; pelo casamento conveniente que recusei; pelo funeral digno que minha fiIha teria, [...]. (CHIZIANE, 1994, p. 131).

Decidida e corajosa, Maria sai em busca de seu amor: "o objeto da minha aventura: o meu homem!". Dessa maneira, vê o retrato de uma mulher de atitude e prevalece a valorização do casamento e da família: "Conheci a verdadeira felicidade ao lado do meu marido". (CHIZIANE, 1994, p. 133). Em Chiziane, não há personagens femininas que rompam a tradição, porém ao focalizarem seus desejos, "pequenos atos de rebeldia e enormes sacrifícios, propicia que elas façam ouvir suas vozes" (MACÊDO, 2003, p. 164-165).

Ao ser questionada pela filha se seria capaz de abandoná-la, Maria responde afetuosa e criticamente: "- Perdoa-me, 
querida. Eu não queria dizer nada. Apenas gostaria que os seres humanos tivessem mais humanidade, amor e fraternidade" (CHIZIANE, 1994, p. 133).

Já o conto "Quantos filhos Natalina teve?", publicado por Conceição Evaristo em 2015, faz uma pergunta e antecipa a personagem principal que é Natalina. Com o narrador em terceira pessoa, a história é introduzida pela cena afetiva da protagonista acarinhando o próprio ventre.

Na primeira gravidez, resultado de seu relacionamento com Bilico, Natalina tinha 14 anos incompletos, sentiu ódio e vergonha, guardou segredo entre ela e a mãe. A primeira solução pensada foi o aborto. Para a mãe de Natalina, a pobreza justificava as alternativas escolhidas, ou os chás ou a parteira Sá Praxedes. Escolhas essas que remetem à sabedoria popular, mas também ao problema social de práticas abortivas ilegais:

Na casa já havia tanta gente! Ela, o marido e sete crianças. E agora teria o filho da filha? la tentar mais um pouco de beberagens, se não desse certo, levaria a menina a Sá Praxedes. A velha parteira cobraria um pouco, mas ficariam livres de tudo. Natalina segurou o temor em silêncio. Sá Praxedes, não! Ela morria de medo da velha. Diziam que ela comia meninos. (EVARISTO, 2016, p. 44- 45).

Há diferenças entre o texto de Evaristo em relação ao texto de Chiziane que devem ser consideradas. Natalina não foi expulsa de casa como Maria. Em sua inocência, ela opta por fugir de casa e, ao ter o bebê, doa-o para uma enfermeira no hospital. 
Na segunda gravidez, também indesejada, Natalina já se mostra mais experiente sexualmente, "brincava gostoso com outros homens, mas não descuidava" (EVARISTO, 2016, p. 46). Entretanto, "semente teimosa vingou". Dessa vez, o pai era Tonho, um migrante, que toma uma atitude protetora em relação à Natalina. Contudo, esta rompe com o comportamento sociocultural esperado, recusando-se ao casamento, ou seja, tem uma postura distinta da personagem Maria. Isso reporta às transformações da sociedade contemporânea.

Ela gostava dele, mas não queria ficar morando com ele. Tonho chorou muito e voltou para a terra dele, sem nunca entender a recusa de Natalina diante do que ele julgava ser o modo de uma mulher ser feliz. Uma casa, um homem, um filho... Voltou levando consigo o filho que Natalina não quis. (EVARISTO, 2016, p. 46).

Evidenciam-se também diferenças no que se refere à linguagem, pois Chiziane apresenta um lirismo próximo do filosófico, já Evaristo é bastante realista e irônica.

A terceira gravidez também foi indesejada para Natalina, mas desejada por seus patrões. Após meses, de um lado, tem-se a alegria do casal; do outro, a náusea de Natalina: "Tudo passava lento, os nove meses de eternidade, os enjoos. O estorvo que ela carregava na barriga faria feliz o homem e a mulher que teriam um filho que sairia dela. Tinha vergonha de si mesma e deles". (EVARISTO, 2016, p.48).

A quarta gravidez foi resultado de violência sexual cometida por um desconhecido, sem nome, sem face: 
Não, dessa vez ela não devia nada a ninguém. Se aquela barriga tinha um preço, ela também tinha tido o seu, e tudo tinha sido feito com uma moeda bem valiosa. Agora teria um filho só seu, sem ameaça de pai, de mãe, de Sá Praxedes, de companheiro algum ou de patrões. E haveria de ensinar para ele que a vida é viver e é morrer. É gerar e é matar. (EVARISTO, 2016, p. 49).

Há a descrição da cena de estupro sofrida pela protagonista após esta ser confundida e sequestrada em seu barraco. Isso revela a vulnerabilidade da mulher, especialmente, pobre e negra. Ela conceberia um filho sem marca, "a semente invasora daquele homem" de quem não viu o rosto (EVARISTO, 2016, p.50).

Estava feliz. O filho estava para arrebentar no mundo a qualquer hora. Estava ansiosa para olhar aquele filho e não ver a marca de ninguém, talvez nem dela. Estava feliz e só consigo mesma. [...]. Brevemente iria parir um filho. Um filho que fora concebido nos frágeis limites da vida e da morte. (EVARISTO, 2016, p.50).

Evaristo desconstrói, nas três primeiras gravidezes, o ideal de que a maternidade é uma realização feminina, pois, no conto, ela não corresponde a um estado divino e abençoado. Na quarta gravidez, embora seja resultado de estupro, Natalina adquire o desejo de ser mãe, após vingar-se do pai da criança, assassinando-o com a sua própria arma (do agressor). 
Nos contos, há questões sociais e existenciais, sendo tratado o tema da sexualidade feminina aliado à maternidade. Evidencia-se a questão do corpo feminino que assume uma postura corajosa de expressar sua intimidade. No texto de Chiziane, há uma construção da imagem materna, pois se busca justificar o (quase) abandono da criança. No entanto, no texto de Evaristo, não se explicitam justificativas (ficam abertas para o leitor), por isso, desconstrói-se a imagem materna, transgredindo o modelo padrão de mãe.

Maria Teresa Salgado (2004, p. 303) pontua que, especificamente Chiziane, expõe uma "reivindicação aberta da sexualidade feminina em um espaço marcado pelo machismo, que se assusta com a 'audácia' da mulher moçambicana na expressão de seus desejos". Nessa mesma direção, Evaristo aborda o corpo e a sexualidade da mulher negra na sociedade brasileira. A imagem de mãe à mulher negra, conforme Evaristo (2009), foi muito negada na literatura brasileira. Para a autora, isto pode significar o apagamento do papel da muIher negra e da matriz africana na formação cultural brasileira. (EVARISTO, 2009).

As autoras realizam a denúncia social nos enredos por meio de personagens mulheres que passam por uma situação vulnerável, algo vivido por inúmeras mulheres pobres, sejam moçambicanas, sejam brasileiras. Ambas as autoras focalizam a mulher e, com sensibilidade, exploram a interioridade feminina e as circunstâncias históricas, sociais e culturais. Nas histórias, são vidas contadas e sofridas, mas que resistem à dor. 


\section{Considerações finaIS}

Os contos abordados são exemplos de textos comprometidos com a realidade com a qual dialogam. A maternidade é uma das atribuições que são conferidas socialmente à mulher. A identidade maternal (o que é ser mãe?), a individualidade, as relações interpessoais e familiares conflituosas são pontos que podem ser observados nos contos. Nota-se a responsabilidade social das escritoras de não apenas apresentar a realidade, mas de denunciá-la, de resistência contra as imposições androcêntricas.

A leitura dos contos de Paulina Chiziane e Conceição Evaristo permite-nos estabelecer aproximações que, na verdade, são diálogos de resistência voltados para a condição feminina. As protagonistas são mulheres que sofreram violência: Maria foi expulsa pelo pai, obrigada a abandonar sua casa; Natalina seria obrigada ao aborto pela mãe, por isso, optou por abandonar sua família, depois, seu corpo serve ao Outro, à procriação e, por fim, tem seu corpo violentado fisicamente. Contudo, as mulheres em cena constroem suas identidades com o passar do tempo, adotando uma postura de autonomia, fazem suas escolhas e decidem suas vidas.

Com uma linguagem marcada por uma consciência política, Chiziane e Evaristo levam à reflexão a condição feminina. Como é construída ou desconstruída a imagem materna nos contos? Nas duas histórias, fala-se sobre mulher-mãe que toma a decisão (ou não) de abandonar um filho e apresenta (ou não) motivos. No lugar da imagem de mãe idealizada, vê-se a mulher que não é obrigada a ser mãe antes de tudo. 
As personagens Maria e Natalina apresentam-se como protótipos de mulheres e, a partir das vidas delas, os contos abordam a vida de várias Marias e Natalinas.

\section{REFERÊNCIAS BIBLIOGRÁFICAS}

CHIZIANE, Paulina. As cicatrizes do amor. ROSARIO, Lourenço do; GODINHO, Maria Luísa (org.) O conto moçambicano: da oralidade à escrita. Rio de Janeiro: Te Cora, 1994, p. 128-133.

DUARTE, Constância Lima. Feminismo e literatura no Brasil. Estudos Avançados. vol.17, n.49. São Paulo, set./dez. 2003. Disponível em <http://www.scielo.br/scielo.php?script=sci_arttext\&pid=S0103-40142003000300010 > . Acesso em 16 jun. 2013.

. O cânone literário e a autoria feminina. In: AGUIAR, Neuma. Gênero e Ciências Humanas: desafio às ciências desde a perspectiva das mulheres. Rio de Janeiro: Record, 1997, p. 85-94.

EVARISTO, Conceição. Quantos filhos Natalina teve? In: Olhos d'água. Rio de Janeiro: Pallas, 2016, p. 43- 50.

- Literatura negra: uma poética de nossa afro-brasilidade. Scripta, Belo Horizonte, v. 13 , n. 25, p. 17-31, $2^{\circ}$ sem. 2009. Disponível em:<http://periodicos.pucminas.br/index. php/scripta/article/view/4365/4510> Acesso em 29 abr. 2017.

GOMES, Heloísa Toller. Prefácio. EVARISTO, Conceição. Olhos d'água. Rio de Janeiro: Pallas, 2016, p. 9- 11. 
HOLLANDA, Heloísa Buarque de. Feminismo em tempos pós-modernos. In: HOLLANDA, Heloísa Buarque de (Org.). Tendências e impasses: o feminismo como crítica da cultura. Rio de Janeiro: Rocco, 1994, p. 7-19.

MACÊDO, Tânia. Estas mulheres cheiras de prosa: a narrativa feminina na África de língua oficial portuguesa. LEÃO, Ângela Vaz (Org.). Contatos e ressonâncias: literaturas africanas de língua portuguesa. Belo Horizonte: PUC Minas, 2003, p. 155- 168.

RESENDE, Beatriz. Contemporâneos: expressões da literatura brasileira do século XXI. Rio de Janeiro: Casa da Palavra, 2008.

. Apontamentos de crítica cultural. Rio de Janeiro: Aeroplano, 2002.

SALGADO, Maria Teresa. Um olhar em direção à narrativa contemporânea moçambicana. SCRIPTA, Belo Horizonte, v. 8, n. 15, p. 297-308, $2^{\circ}$ sem. 2004. Disponível em: <http:// www.ich.pucminas.br/cespuc/Revistas_Scripta/Scripta15/ Conteudo/N15_Parte03_art07.pdf>Acesso em 13 ago. 2017.

SHOWALTER, Elaine. A crítica feminista no território selvagem. Tradução Deise Amaral. In: HOLLANDA, Heloísa Buarque (org.). Tendências e impasses: o feminismo como crítica da cultura. Rio de Janeiro: Rocco, 1994, p. 23-57. 
SOIHET, Rachel. História, mulheres, gênero: contribuições para um debate. In: AGUIAR, Neuma. Gênero e Ciências Humanas: desafio às ciências desde a perspectiva das mulheres. Rio de Janeiro: Record, 1997, p. 95-114.

ZINANI, Cecil Jeanine Albert. História da literatura: questões contemporâneas. Caxias do Sul: Educs, 2010.

Submissão: 30/08/2017

Aceite: $24 / 10 / 2017$ 